\title{
A Rare Cause of Acute Respiratory Distress Syndrome
}

\section{Babu Sah R and Gothi D*}

Department of Pulmonary Medicine, Employee State Insurance- Post Graduate Institute of Medical Science and Research (ESI-PGIMSR), Delhi, India

\begin{abstract}
A 25-year-old lady presented with acute respiratory distress syndrome following dilatation and curettage. Due to non-responding fever she was investigated further. High resolution computed tomography showed 'random nodules' with consolidation suggestive of miliary tuberculosis with acute respiratory distress syndrome, which was confirmed later on transbronchial lung biopsy. She responded to antituberculous therapy and was discharged afebrile with normal vital parameters.
\end{abstract}

Keywords: Acute respiratory distress syndrome; High resolution computed tomography; Random nodules; Miliary tuberculosis

Abbreviations: Acute respiratory distress syndrome: ARDS; High resolution computed tomography: HRCT; Tuberculosis: TB; Dilatation and curettage: D \& C

\section{Introduction}

Miliary tuberculosis is a potentially fatal form of tuberculosis, occurs due to haematogenous spread of Mycobacterium tuberculosis. Diagnosis is often delayed because of non-specific clinical manifestations. Cryptic miliary tuberculosis is even more difficult to diagnose because of normal chest radiograph. Rarely miliary TB can lead to acute respiratory distress syndrome. We report a case of cryptic miliary tuberculosis, which presented with acute respiratory distress syndrome following dilatation and curettage.

\section{Case Report}

A 25-year-old woman, housewife, was referred from postoperative intensive care unit for respiratory distress following the $\mathrm{D} \& \mathrm{C}$ for threatened abortion. She gave history of intermittent low-grade fever of 5 weeks duration. Beside this there were no significant past history. Her vitals before shifting to intensive care unit from procedure room were: pulse rate- $140 / \mathrm{min}$, respiratory rate- $32 / \mathrm{min}$, and blood pressure of $108 / 70 \mathrm{~mm} \mathrm{Hg}$ and oxygen saturation of $75 \%$ at room air. Bilateral fine basal crackles were auscultated on respiratory system examination. Other system examination was normal.

Patient was investigated. Her arterial blood gas analysis at $\mathrm{FiO}_{2}$ of $21 \%$ (room air) revealed $\mathrm{pH}-7.459, \mathrm{PCO}_{2}-34.3 \mathrm{~mm}$ of $\mathrm{Hg}$, $\mathrm{PO}_{2}-33.5 \mathrm{~mm}$ of $\mathrm{Hg}, \mathrm{SpO}_{2}-67.8$ and $\mathrm{HCO}_{3}-24.6 \mathrm{mEq} / \mathrm{L}$, with $\mathrm{PO}_{2} /$ $\mathrm{FiO}_{2}$ ratio of $159.5 \mathrm{~mm}$ of $\mathrm{Hg}$ suggestive of acute respiratory distress syndrome (ARDS). She was started empirically on injectable antibiotics (imipenem, gentamicin and levofloxacin) for suspected genitourinary infection and septicemia, steroids for ARDS, and non-invasive ventilation for acute respiratory failure with a working diagnosis of ARDS secondary to septicemia. There was no evidence of giving intravenous fluid during the procedure. Initial biochemical reports were normal. Her haemogram showed haemoglobin $-9.4 \mathrm{gm} / \mathrm{dl}$, total leucocyte count of $6300 / \mathrm{mm} 3$ with normal differential cell percentage. Enzyme link immunosorbant assay for human immunodeficiency virus was negative. The chest radiograph prior to surgery was available, is shown in Figure 1. The chest radiograph in the ICU is shown in Figure 2. Transvaginal sonography was normal. Widal test for enteric fever, peripheral smear for malarial parasite, dengue serology, blood culture

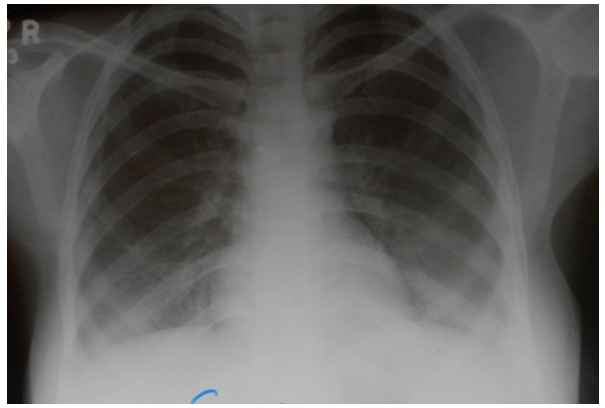

Figure 1: Chest radiograph prior to $D \& C$ showing doubtful left sided pleural effusion.

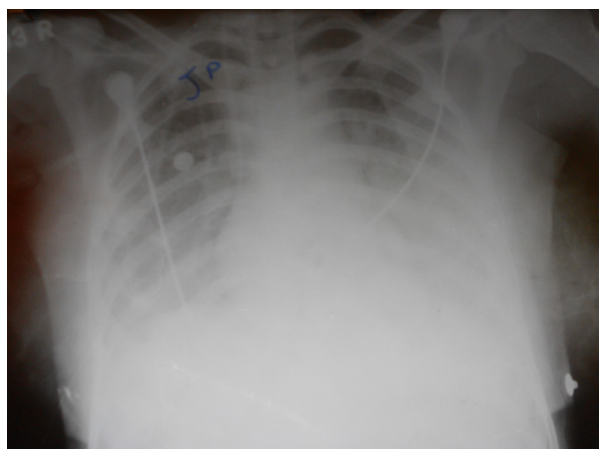

Figure 2: Chest radiograph following $D$ \& $C$ showing bilateral consolidation.

and urine culture were negative. The histopathology of specimen obtained after D \& C showed only decidua without any evidence of infection. Echocardiography revealed trivial mitral regurgitation with

*Corresponding author: Dipti Gothi, Professor, Department of Pulmonary Medicine, ESI- PGIMSR, Delhi, New Delhi - 110015, Tel: +91-9971550550; Fax: 011 25970860; Email: diptigothi@gmail.com

Received February 12, 2016; Accepted February 27, 2016; Published March 01,2016

Citation: Sah RB, Gothi D (2016) A Rare Cause of Acute Respiratory Distress Syndrome. J Clin Respir Dis Care 2: 108. doi: 10.4172/2472-1247.1000108

Copyright: (C) 2016 Sah RB, et al. This is an open-access article distributed under the terms of the Creative Commons Attribution License, which permits unrestricted use, distribution, and reproduction in any medium, provided the original author and source are credited. 
Citation: Sah RB, Gothi D (2016) A Rare Cause of Acute Respiratory Distress syndrome. J Clin Respir Dis Care 2: 108. doi: 10.4172/24721247.1000108

normal ejection fraction. The patient was transferred to ward after 5 days with partial improvement. Fever during the ICU stay had reduced but on omitting levofloxacin, gentamicin and imipenem the fever spikes increased. HRCT thorax was advised for non-responding fever, showed bilateral ground glass opacity with patchy consolidation in both upper lobes and dense consolidation in both lower lobes. It also showed presence of 'random nodules' in both lung fields with bilateral pleural effusion (Figure 3). The patient was started on anti-tuberculosis treatment based on HRCT finding. Transbronchial lung biopsy was performed after partial clinical improvement, which showed epitheloid cell granuloma with necrosis on histopathology (Figure 4). Fever responded and she was discharged with normal vital parameters. One month after the discharge chest radiograph and HRCT were repeated and are shown in Figures 5 and 6.

\section{Discussion}

Acute respiratory distress syndrome describes a condition characterized by the acute onset of bilateral infiltrates on chest radiograph, hypoxaemia (defined as a $\mathrm{PaO}_{2} / \mathrm{FiO}_{2}$ ratio of $<200 \mathrm{mmHg}$ ) and no evidence of left atrial hypertension [1]. As per the new definition ARDS is categorized into mild, moderate and severe ARDS. Our case had findings consistent with moderate ARDS i.e. $\mathrm{PaO}_{2} / \mathrm{FiO}_{2}$ between 100-200 mmHg [2]. Miliary tuberculosis is a rare cause of ARDS [3,4]. However, the mortality is very high ranges from $33 \%$ to as high as $100 \%, 4$ which is far higher than for ARDS from other causes. Due to low causal association, the diagnosis of miliary tuberculosis as the cause of ARDS is delayed or often missed.

Early diagnosis and timely treatment due to characteristic HRCT abnormality saved our patient. The HRCT showed areas of consolidation with "random nodules". "Random nodules" are small
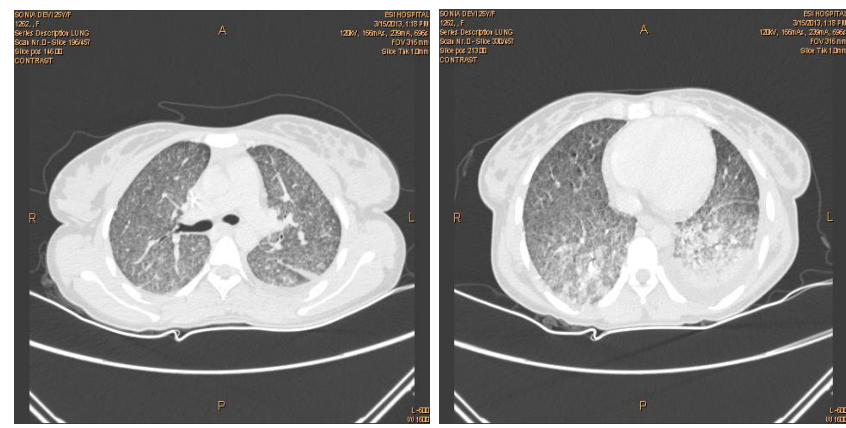

Figure 3a and 3b: HRCT thorax showing presence of 'random nodules' in both upper lobes and consolidation and effusion in both lower lobes.

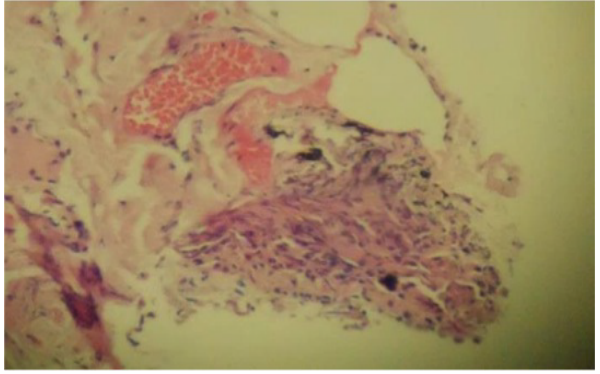

Figure 4: Transbronchial lung biopsy showing epitheloid granuloma with necrosis.

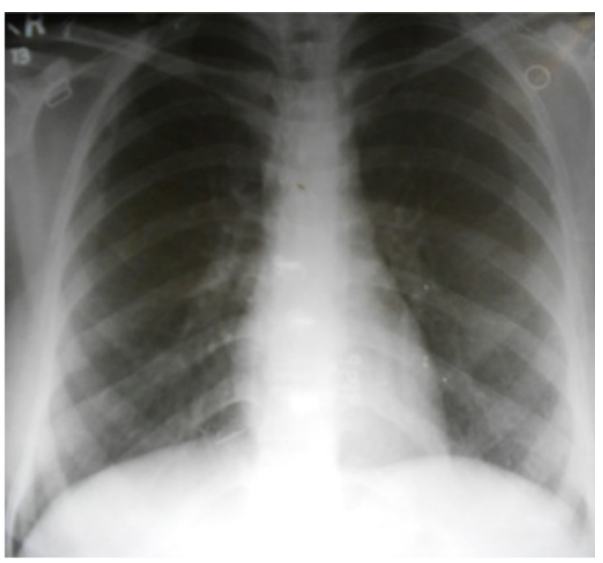

Figure 5: Normal chest radiograph after 1 month of treatment.

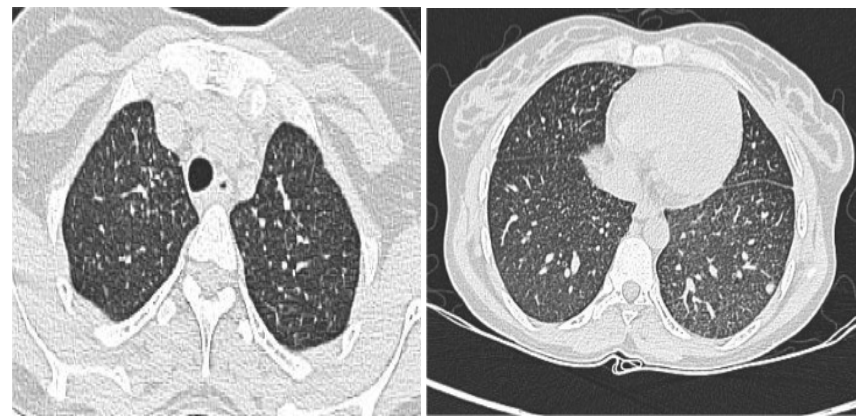

Figure $6 \mathrm{a}$ and $6 \mathrm{~b}$ : HRCT thorax after 1 month of treatment showing improvement but persistence of a few random nodules confirming 'cryptic miliary'.

nodules seen on HRCT distributed haphazardly throughout the lungs along the pleura and fissures, at the ends of small arteries, and also in a centrilobular location [5]. These nodules on HRCT are seen in miliary tuberculosis, fungal infection, and metastasis and Langerhans cell histiocytosis. Possibility of fungal infection was low because she was immunocompetent. Metastasis was also unlikely because of young age and absence of primary malignancy. Langerhans cell histiocystosis was also unlikely because of fever and relatively acute onset of disease. Hence, on clinico-radiological correlation the most plausible diagnosis was miliary tuberculosis presenting with ARDS. The diagnosis was further proved on lung biopsy.

The possible mechanism of ARDS is that tuberculosis causes accumulation of inflammatory cells in the alveolar spaces leading to release of granular enzymes and oxidants resulting in damage to the alveolar basement membrane. Increase in cellular permeability due to alveolar basement damage aggravates oxygen dysfunction and consequently causes ARDS [6].

The predisposing factors for development of ARDS in a case of miliary TB are prolonged illness, absolute lymphocytopaenia, elevated alanine transferase (ALT), aspartate transaminase (AST), diabetes mellitus, D-dimer, low hemoglobin, and albumin [7,8]. None of the studies have shown surgery as a risk factor for development of ARDS. However surgery is known to disseminate unrecognized tuberculosis [9]. D \& C possibly led to the development of ARDS in our case with existing 'cryptic miliary TB', which was missed during preoperative evaluation. 'Cryptic miliary TB' often remains undiagnosed because 
Citation: Sah RB, Gothi D (2016) A Rare Cause of Acute Respiratory Distress syndrome. J Clin Respir Dis Care 2: 108. doi: 10.4172/24721247.1000108

typical chest radiograph findings are not absent. D \& C thus can be added as a risk factor for development of ARDS due to miliary TB.

Initial mortality due to ARDS in our patient was averted possibly because of antimycobacterial action of gentamicin [10], levofloxacin and imipenem [11]. Partial response of ARDS and miliary TB can only be explained by antimycobacterial action of antibiotics, as she had no evidence of pyogenic infection. Steroid also had possibly helped our patient because promising results regarding the efficacy of steroids as a treatment modality for ARDS caused by miliary tuberculosis has been reported [12].

In conclusion, thorough preoperative evaluation is indicated prior to any surgery. Presence of 'random nodule' is an important clue to the diagnosis of miliary TB in a case of ARDS. Early diagnosis and prompt treatment of ARDS due to miliary TB averts mortality.

\section{Acknowledgement}

We would like to thank Dr. Suprithi Kohli, HOD, and Radiology for providing the images.

\section{References}

1. Bernard GR, Artigas A, Brigham KL, Carlet J, Falke K, et al. (1994) The American-European Consensus Conference on ARDS. Definitions, mechanisms, relevant outcomes, and clinical trial coordination. Am J Respir Crit Care Med 149: 818-824.

2. Ranieri VM, Rubenfeld GD, Thompson BT, Ferguson ND, Caldwell E, et al. (2012) Acute Respiratory Distress Syndrome. The Berlin Definition. JAMA 307 : 2526-2533.
3. Mohan A, Sharma SK, Pande JN (1996) Acute respiratory distress syndrome (ARDS) in miliary tuberculosis: a twelve year experience. Indian J Chest Dis Allied Sci 38: 157-162.

4. Kim JY, Park YB, Kim YS, Kang SB, Shin JW, et al. (2003) Miliary tuberculosis and acute respiratory distress syndrome. Int $\mathrm{J}$ Tuberc Lung Dis 7: 359-364.

5. Boitsios G, Bankier AA, Eisenberg RL (2010) Diffuse Pulmonary Nodules. AJR 194: W354-W366.

6. Matuschak GM, Lechner AJ (2010) Acute lung injury and the acute respiratory distress syndrome: pathophysiology and treatment. Mo Med 107: 252-258.

7. Sharma SK, Mohan A, Banga A, Saha PK, Guntupalli KK (2006) Predictors of development and outcome in patients with acute respiratory distress syndrome due to tuberculosis. Int J Tuberc Lung Dis 10: 429-435.

8. Deng W, Yu M, Ma H, Hu LA, Chen G, et al. (2012) Predictors and outcome of patients with acute respiratory distress syndrome caused by miliary tuberculosis: a retrospective study in Chongqing, China. BMC Infectious Diseases 12: 121-122.

9. Salem B (2008) Disseminated tuberculosis following the placement of ureteral stents: a case repot. Cases J 1: 383-386.

10. Ho YI, Chan CY, Cheng AFB (1997) In-vitro activities of aminoglycosideaminocyclitols against mycobacteria. J Antimicrob Chemother 40: 27-32.

11. Chambers HF, Turner J, Schecter GF, Kawamura M, Hopewell PC (2005) Imipenem for Treatment of Tuberculosis in Mice and Humans. Antimicrob Agents Chemother 49: 2816-2821.

12. Sun TN, Yang JY, Zheng LY, Deng WW, Sui ZY (1981) Chemotherapy and its combination with corticosteroids in acute miliary tuberculosis in adolescents and adults: analysis of 55 cases. Chin Med J (Engl) 94: 309-314. 